\title{
System dynamics modelling and simulating the effects of intellectual capital on economic growth
}

\author{
Ivona Milić Beran ${ }^{1, *}$ \\ ${ }^{1}$ Maritime Department, University of Dubrovnik \\ Ćira Carića 4, 20000 Dubrovnik, Croatia \\ E-mail: 〈\{imberan\}@gmail.com〉
}

\begin{abstract}
System dynamics modelling is one of the best scientific methods for modelling complex, nonlinear natural, economic and technical system dynamics as it enables both monitoring and assessment of the effects of intellectual capital on economic growth. Intellectual capital is defined as "the ability to transform knowledge and intangible assets into resources to create wealth for a company and a country." Transformation of knowledge is crucial. Knowledge increases a country's wealth only if its importance is recognized and applied differently from existing work practices. The aim of this paper is to show the efficiency of modelling system dynamics and simulating the effects of intellectual capital on economic growth. A computer simulation provided a mathematical model, providing practical insight into the dynamic behavior of the observed system, i.e. the analysis of economic growth and observation of mutual correlation between individual parameters. The results of the simulation are presented in graphical form. The dynamic model of the effects of intellectual capital on Croatia's economic growth has been verified by comparing simulation results with existing data on economic growth.
\end{abstract}

Key words: intellectual capital, economic growth, system dynamics, structural model, development diagram

Received: September 30, 2014; accepted: May 6, 2015; available online: October 31, 2015

DOI: $10.17535 /$ crorr.2015.0034

\section{Introduction}

The subject of this paper is qualitative and quantitative system dynamics modelling of the effects of intellectual capital on economic growth. Intellectual capital is an important factor in economic growth, both directly and indirectly for Croatia's economic growth. The methodology of system dynamics modelling, which has been rarely used in researching economic issues, is nonetheless treated in this paper. It integrates existing knowledge and contributes to a better understanding of newly created relationships between complex natural and

${ }^{*}$ Corresponding author. 
social economic systems. The methodology can also be applied to assessing a wide range of scenarios and creating better strategies to meet the modern world's developmental trends. [1]

Devising the system dynamics model requires:

- Analysis of intellectual capital,

- Creating a system dynamics structural and a mental-verbal model of the impact of intellectual capital on economic growth,

- Creating a mathematical model of economic growth,

- Analyzing the effects of intellectual capital on Croatia's economic growth.

The scenario established to analyze the effects of intellectual capital variations on economic growth spans a 12-year period (1999-2010), and aims to obtain answers to the question, "To what extent would an increase in intellectual capital affect Croatia's economic growth?"

\section{Review of literature}

Human capital, innovation and technology transfers are vital when drawing up a model of intellectual capital and its relationship network. These factors are known to boost the creation and exchange of information and knowledge in different socio-economic circles. A number of papers emphasize the importance of intellectual capital, or some of its components, in economic development. Capella and Nijkamp [2] used human and knowledge capitals, Cook et al. [3] has used knowledge, Acs et al. [4] innovation. Yeh-Yun Lin and Edvisson [5] have said that intangibles are one of the most important sources of prosperity and progress. Navarro et al. [6] has studied the relationship between national intellectual capital and GDP and shown that it is a positive relationship. Manzari et al. [7] have presented a general review of intellectual capital literature, which includes definitions, components and indicators. There are many economic models created by following the system dynamics paradigm: Forrester's [8] national economic model, macroeconomic models created by Sterman [9], the Millennium Institute [10], Radzicki [11], Yamaguchi [12], Munitic's economic model of Croatia [13], Milić Beran [14], Sovilj et al. [15]. Despite these papers on intellectual capital and system dynamic economic models, there is a lack of papers describing the effects of intellectual capital on economic growth in a system dynamic approach. 


\section{Intellectual capital and economic growth}

Economic growth results from assessing economic objectives, achievable using available resources, core competencies and an infusion of large investments into human, intellectual, technological and social capital.

Intellectual capital is essential for maintaining competitiveness, hence a valid source for creating wealth. Intellectual capital management develops wealth in business as the potential of intellectual capital for the economy is recognized and used in opening up possibilities for future business growth. The quality and range of organizational abilities and responsibilities is of great significance, hence maximum development of these resources is crucial for economic development.

Bradley [16] defines intellectual capital as "the ability to transform knowledge and immaterial property into resources that produce wealth for companies and the country as well". A completely different appreciation of knowledge is crucial, as it increases wealth only if its significance is recognized and used differently. Bradley, when discussing intellectual capital inviolability, defines it as a characteristic of future wealth development.

Science and technology, theory and practice, and appropriate social conditions are increasingly being linked into a single chain, which promotes further economic growth. Generally, economic and social dynamics are of great interest, but not easy to understand because socio-economic systems are complex, and they are made up of interdependent subsystems.

Croatia's economic growth (GR) is presented here as an entity consisting of the four subsystems (Figure 1): RR - working resources, KD - Capital assets, LJK - Human Capital and TK - Technological Capital

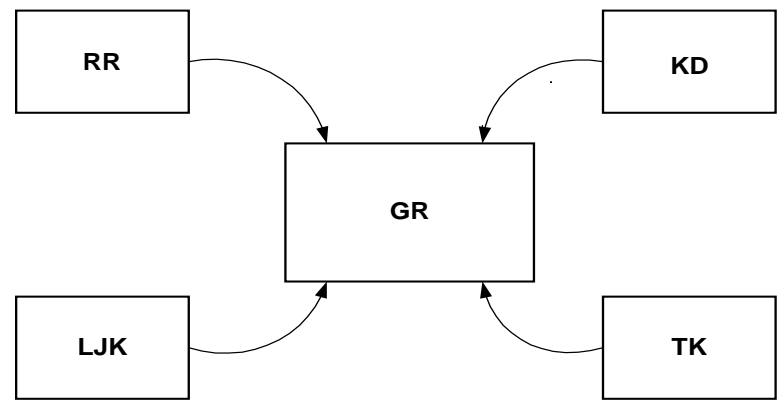

Figure 1: Model of Economic growth of Croatia

\footnotetext{
${ }^{1}$ Source:According Milić Beran, 2012.
} 
These subsystems communicate with their relevant environment consisting of: education, industry, investment, the technology of advanced countries, moral capital, social capital, psychological capital, population, etc.

It is impossible to directly and exactly measure the effects of intellect capital on economic growth. This paper examines indirectly the effects of intellect capital (IK) on economic growth (GR), through changes in human capital (LJK), technological capital (TK) as well as the results of education $(\mathrm{O})$ and research work (IST) (Figure 2).

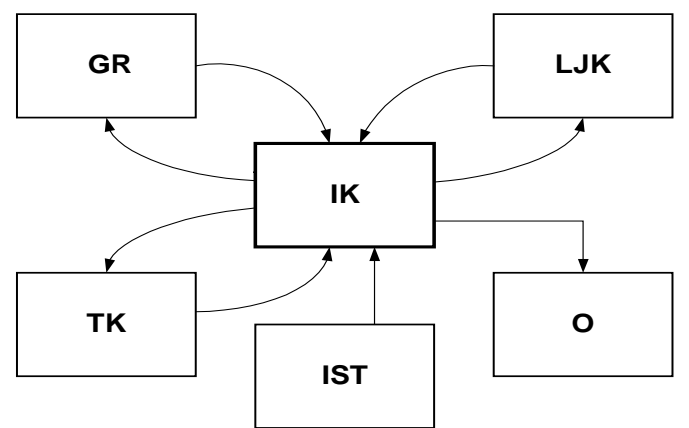

Figure 2: The rudimentary and analogous flow-communication between intellectual capital and other sub-systems of economic growth ${ }^{2}$

At least one material, energy or information flow is particularly important for the behavioral dynamics of complex systems or its four subsystems circulating through communication channels such as: population, political information, cultural, scientific, technological information flow, etc.

\section{System dynamic structural and mental-verbal intellectual capital model}

Qualitative modeling is a starting point in the modeling process. A structured and integrated casual loop diagram follows a mental presentation of the observed system. [17]

The structural model, shown in Figure 3, is designed based on the analysis of parameters affecting intellectual capital. The basic parameters of the model are relative changes in human capital, education, technological capital, economic growth and intellectual capital.

The intellectual capital rate (SIK) is mostly affected by tertiary education (O), research work (IST), human capital (LJK) and economic growth (GR). As the intensity of tertiary education $(\mathrm{O})$ increases, the intellectual capital rate (SIK) increases. At the same time, the more intense research work (IST)

${ }^{2}$ Source: According Milić Beran, 2012 
becomes, the higher the intellectual capital rate (SIK), meaning that the effect of these parameters on the intellectual capital rate (SIK) is positive. The conclusion is that the internal relations between (O), (IST) and (SIK) have a positive, dynamic character. As the intellectual capital rate (SIK) increases, the relative value of intellectual capital (IK) increases as well.

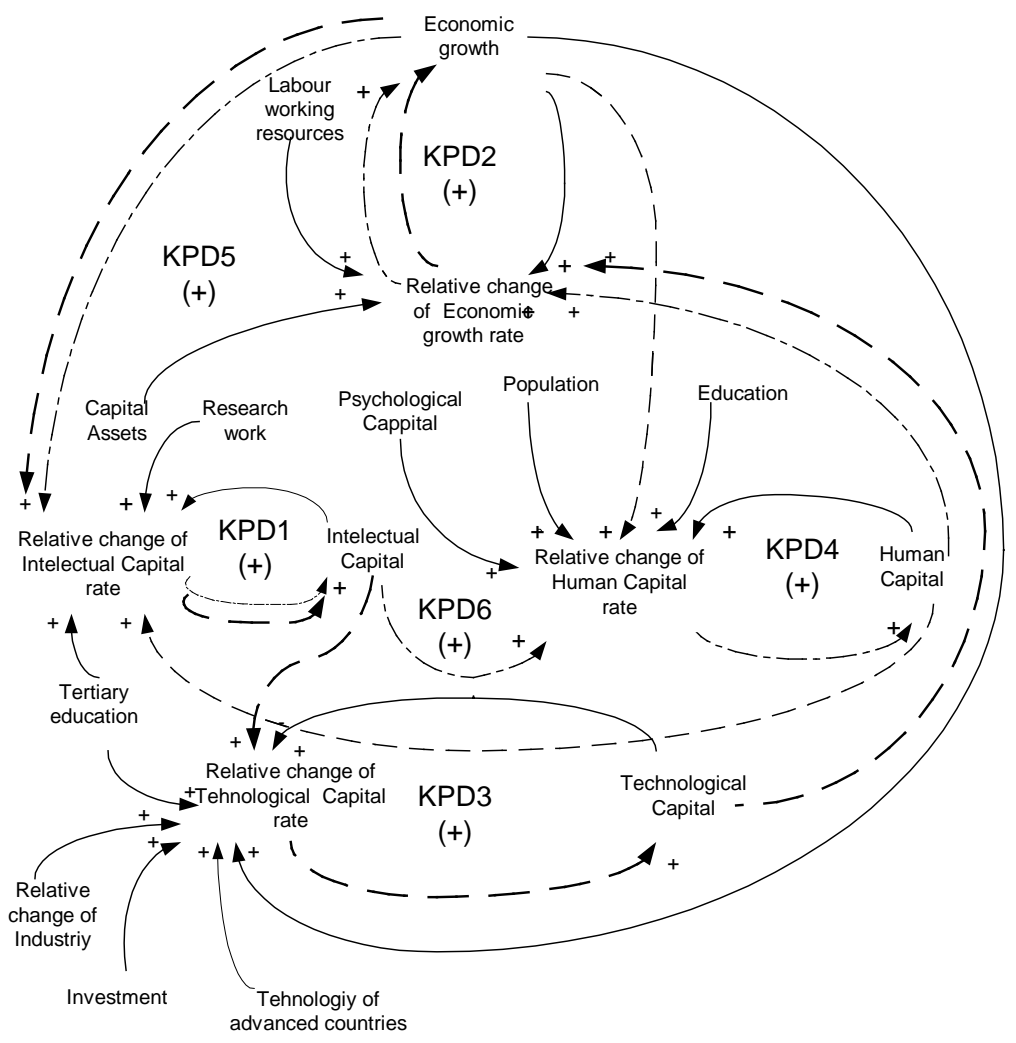

Figure 3: Intellectual capital structural diagram

Feedback loop KPD1 includes a link between the intellectual capital rate SIK and intellectual capital IK. The link between the economic growth rate SGR and economic growth GR is describe by feedback loop KPD2. These feedback links have a positive dynamic character, meaning that feedback loops KPD1 and KPD2 have a globally positive character. Feedback loop KPD3 comprises links between technological capital TK and the technological capital rate STK, and has a positive dynamic character. Feedback loop KPD4 comprises links between human capital LJK and the human capital rate SLJK, and has a positive dynamic character. 
Feedback loop KPD5 includes links between: IK - STK - TK - SGR - GR - SIK - IK. All the mentioned links are positive, meaning that the feedback loop has a global positive character.

Feedback loop KPD6 includes links between: IK - SLJK - LJK - SGR GR - SIK - IK, where the dynamic characteristics of these internal links are positive, hence feedback loop KPD6 has a positive dynamic character.

The flow diagram is a quantitative system model that highlights the basic physical system structure and provides more information than a structural diagram. The stock and flow moral capital diagram in the DYNAMO symbol (see Figure 4) has been created based on the structural and mental-verbal model.

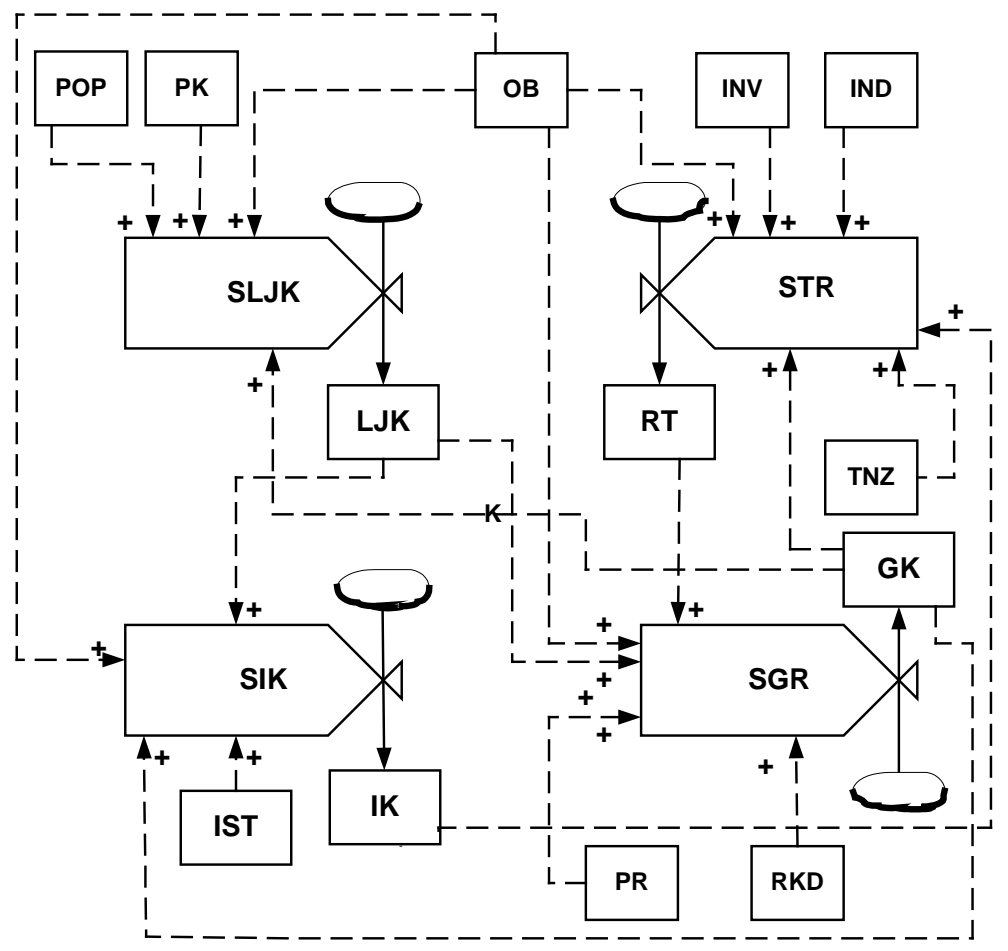

Figure 4: Stock and flow intellectual capital diagram

Figure 4 shows four basic stock and flow diagram characteristics:

- System stocks,

- Flows among stocks,

- Control function of matter, energy or information flowing between the system stocks,

- Information channels connecting the system stocks with the control function [18]. 
The values of investment INV, research IST, corruption KOR, education OB, government institution credibility POV, work resources RR, grey economy $\mathrm{SE}$, unemployment $\mathrm{N}$, productivity $\mathrm{PR}$, industry RIND, population $\mathrm{POP}$, capital goods RKD and technology of advanced countries TNZ are calculated. ${ }^{3}$ Since the values of the variables have different measurement units, for example, investments denoted in HRK, education denoting the number of people possessing a certain level of education, corruption and the corruption perception index, etc. all values are expressed in relative terms.

\section{Mathematical model of the effect of intellectual capital on economic growth}

Having defined the problem, i.e., the first stage of system dynamics modelling, the second stage or system conceptualization takes place. It includes development of a mathematical model based on the devised cause-effect diagrams as well as the structural system model. The stage of developing the mathematical model is crucial in the system dynamics modelling process. The dynamic mathematical model is created theoretically by applying the basic laws of the system's behavior.

The Cobb-Douglas formula is the fundamental starting point for developing the mathematical model of the effect of intellectual capital on economic growth.

$$
\begin{gathered}
G R=G R_{0}+\int_{t_{1}}^{t_{2}} S G R d t \\
S G R=\frac{d}{d t}\left(k_{1} * T K+k_{2} * R K D+k_{3} * L J K+k_{4} * R R\right)
\end{gathered}
$$

GR in the equation (1) represents a relative value of Croatia's economic growth at a specific time interval and is calculated by adding the economic growth value and the Croatian economic growth integral change from the preceding time interval.

SGR stands for the relative change rate of economic growth which is equal to the first economic growth derivation and is obtained by summing the technological capital relative value TK, the capital goods relative value RKD, the human capital relative value LJK as well as the work resources relative value $R R$ multiplied with the corresponding coefficient indicated in the equation (2).

Human capital, intellectual capital, moral capital, psychological capital, technological capital and social capital can be calculated according to the following equations:

\footnotetext{
${ }^{3}$ The data from the Central Bureau of Statistics, Transparency International and World Bank.
} 


$$
\begin{gathered}
L J K=L J K_{0}+\int_{t_{1}}^{t_{2}} S L J K d t \\
\text { SLJK }=\frac{d}{d t}\left(k_{9} O B^{*} K S G R O+k_{11} P O P+k_{19} P K+k_{35} I K\right) \\
I K=I K_{0}+\int_{t_{1}}^{t_{2}} S I K d t \\
S I K=\frac{d}{d t}\left(k_{29} O * K S G R O+k_{30} L J K+k_{13} I S T\right) \\
M K=M K_{0}+\int_{t_{1}}^{t_{2}} S M K d t \\
\text { SMK }=\frac{d}{d t}\left(k_{25} S K-k_{26} K O R-k_{27} S E\right) \\
P K=P K_{0}+\int_{t_{1}}^{t_{2}} S P K d t \\
S P K=\frac{d}{d t}\left(k_{17} P R-k_{12} N+k_{18} O * K S G R O+k_{20} L J K+k_{24} S K\right) \\
S K=S K_{0}+\int_{t_{1}}^{t_{2}} S S K d t \\
S S K=\frac{d}{d t}\left(k_{21} P K+k_{22} P O V+k_{23} R R+k_{28} M K\right) \\
T K=T K_{0}+\int_{t_{1}}^{t_{2}} S T K d t \\
\left.d k_{5} T N Z+k_{6} R I N D+k_{7} * I N V * K S G R+k_{8} O * K S G R O+k_{31} I K\right)
\end{gathered}
$$


on economic growth

\section{Simulation and verification of the model of the effect of moral capital on Croatia's economic growth}

The dynamic model of the effect of intellectual capital on Croatia's economic growth has been verified by comparing simulation results (SIBDP) with existing results (TBDP) of the economic growth data, as shown in Figure 5.

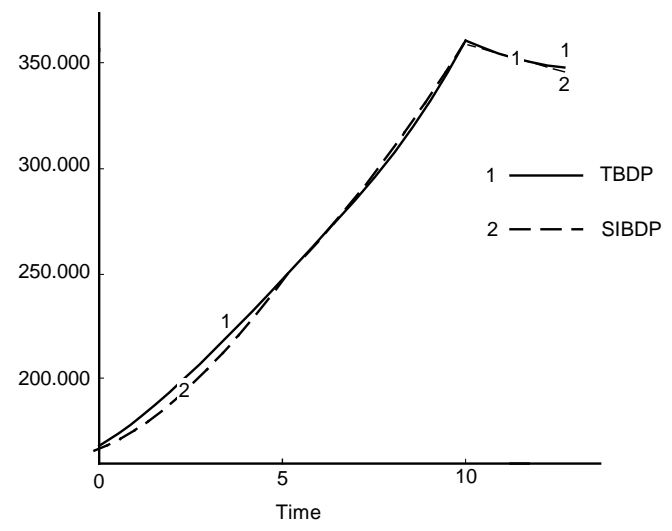

Figure 5: Simulation and existing results of economic growth

Figure 5 shows that the dynamic behavior of modelling the effect of intellectual capital on Croatia's economic growth conforms to relevant information obtained from a real model. The results of the simulation have given expected results.

The effect of intellectual capital on economic growth can be analyzed by simulating the effect of individual parameters on intellectual capital as shown in Scenario 1.

\section{Scenario 1}

A change of intellectual capital occurs in accordance with the step function STEP $(8, .1)$. The step function is used for checking the model's response. The model's response to a step input is often a good indicator of its response to various inputs. Figure 6 shows the effect of the initial condition on economic growth. 


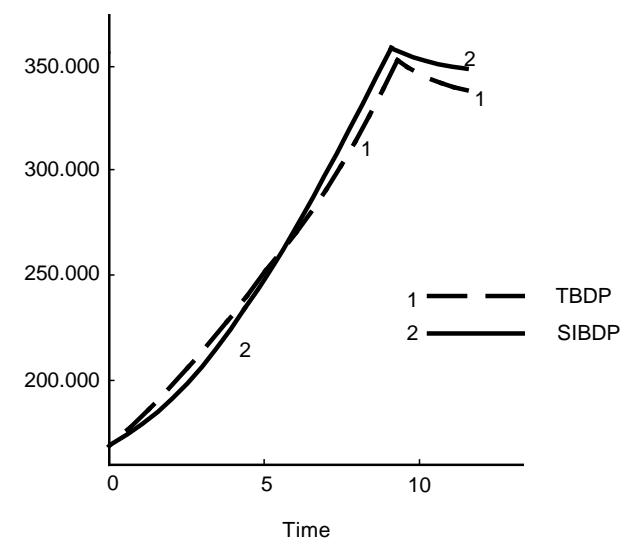

Figure 6: Existing and simulation results according Scenario 1 of economic growth

Curve 1 in Figure 6 shows real economic growth while Curve 2 shows the effect of changes in intellectual capital on economic growth. An increase in GDP under these changes was $3.5 \%$ last year.

\section{Scenario 2}

The ability to increase economic growth by changing factors such as the effect of changes in intellectual capital will be displayed in the Scenario 2. This later scenario assumes an increased effect of intellectual capital on human capital by changing the value of the multiplier K9 from 1 to 1.2.

Data in Table 1 shows the effect of the given initial condition on economic growth.

\begin{tabular}{|c|c|c|}
\hline Time & TBDP & SBDP \\
\hline 0 & 164054.00 & 164054.00 \\
\hline 1 & 176686.16 & 172496.09 \\
\hline 2 & 190794.80 & 185799.37 \\
\hline 3 & 208217.34 & 202265.85 \\
\hline 4 & 227001.52 & 225368.72 \\
\hline 5 & 245539.62 & 245440.47 \\
\hline 6 & 264356.62 & $266 \quad 817.77$ \\
\hline 7 & 286323.45 & 291536.78 \\
\hline 8 & 314196.22 & 317097.78 \\
\hline 9 & 342134.62 & 347005.10 \\
\hline 10 & 333046.03 & 342379.18 \\
\hline 11 & 328124.41 & 339608.00 \\
\hline
\end{tabular}

Table 1: Existing and simulated GDP according to Scenario 2. 
TBDP was the real GDP in the period from 1999 to 2010, and SIBDP the simulated GDP according to Scenario 2. An increase in GDP under these changes was $3 \%$ in a year.

Scenario 1 shows the model's response to a step input in intellectual capital while Scenario 2 shows the model's behavior if the effect of intellectual capital on human capital is increased. The two tested scenarios show that a positive change of intellectual capital has a significant effect on economic growth.

\section{Conclusion}

The system dynamics methodology is relevant, as it comprises not only computer modelling but also clearly determines the mental, structural and mathematical modelling of actual system models. It is a modern method of analyzing the dynamic behavior of a complex system. The system dynamics models provide the opportunity to analyze the results of particular parameters interacting and reactions to individual factors changing. Both qualitative and quantitative system dynamics modelling of the effects of intellectual capital on economic growth have been presented in this paper. Science and technology, theory and practice, and appropriate social conditions are increasingly being linked into a single chain, promoting further economic growth. The structural dynamic model facilitates visual presentation of complex systems, such as the intellectual capital system and the economic growth system. Both the structural dynamic model and the development diagram have been devised based on the mental-verbal model. The above-mentioned models have been used to create a mathematical and simulation model of economic growth. The results obtained in this paper show that investment in intellectual capital contributes significantly to economic growth, and affects both directly and indirectly other economic factors. According to the results, the conclusion is that a rapid economic growth in Croatia cannot be achieved without particular emphasis on investing in intellectual capital. Since intellectual capital depends on several parameters, future research work will analyze the effects of certain parameters on intellectual capital and economic growth, for example the effect of higher education and investment in research and development.

\section{References}

[1] Forrester, W. J. (1975). Collected Papers of Jay W. Forrester. Massachusetts: Wright-Allen Press.

[2] Capella, R. and Nijkamp, P. (2009). Handbook of Regional Growth and Development Theories. Cornwall: Edward Elgar. 
[3] Cook, P., Laurentis, C., Todtling, F. and Tripp, M. (2007). Regional Knowledge Economies. Cornwall: Edward Elgar.

[4] Acs, Z. J., de Groot, H. L. F. and Nijkamp, P. (2002). The Emergence of the Knowledge Economy: A Regional Perspective: Springer et al.

[5] Yeh - Yun Lin, C. and Edvisson, L. (2010). National Intellectual Capital: A Comparison of 40 Countries: Springer.

[6] Navarro, J. L. A, Ruiz, V. R. L. and Pena, D. N. (2011). Estimation of intellectual capital in the European Union using a knowledge model. Zbornik radova Ekonomskog fakulteta u Rijeci (Proceedings of Rijeka Faculty of Economics), 29, 109-132.

[7] Manzari, M., Kazemi, M., Nazemi, S. and Pooya, A. (2012). Intellectual capital: Concepts, components and indicators: A literature review. Management Science Letters, 2(7), 2255-2270. doi:10.5267/j.msl.2012.07.018.

[8] Forrester (1980). Information sources for modeling the national economy. Journal of the American Statistical Association, 75(371), 555-567. doi:10.2307/2287647.

[9] Sterman, J. (2000). Business Dynamics: Systems Thinking and Modeling for a Complex World. Irwin- McGraw-Hill, New York

[10] Millennium Institute (2007). Introduction and purpose of threshold 21. http://www.millenniuminstitute.org/resources/elibrary/papers/T210verview.p $\mathrm{df}$

[11] Radzicki, M. (2007). Institutional economics, post Keynesian economics, and system dynamics: Three strands of a heterodox economics braid. In: Harvey, John T. and Robert F. Garnett, Jr. (eds) The Future of Heterodox Economics, University of Michigan Press, Ann Arbor, Michigan.

[12] Yamaguchi, K. (2007). Balance of payments and foreign exchange dynamics - SD Macroeconomic Modeling (4), In: Sterman, J, R. Oliva, R, Langer, J. Rowe, J. Yanni (eds) Proceedings of the of the Twenty-Fifth International Conference of the System Dynamics Society, Available at http://www.systemdynamics.org/

[13] Munitić, A. (1991). System dynamics computer simulation model of Croatia. SYSTEM DYNAMICS 9, 386-396.

[14] Milić Beran, I. (2012). Modeliranje i simulacija gospodarskog rasta Republike Hrvatske metodom sistemske dinamike, (System dynamics modelling and simulation of Croatia's economic growth). Ph.D. theses, J. J. Strossmayer University of Osijek, Faculty of Economics, Osijek.

[15] Sovilj, S., Tkalec, M., Kostanjčar, Z. and Pripužić, D. (2014) Nacionalni model dinamike hrvatskog ekonomskog sustava (National model of the dynamics of the croatian economic system). Available at http://www.eizg.hr/hr-HR/

[16] Bradly, K. (1997). Intellectual capital and the new wealth of nations. Business Strategy Review, 8(1), 53-70.

[17] Munitić, A. and P. Ristov. (2009). Sistemska dinamika (System Dynamics). University of Split - Faculty of Maritime Studies.

[18] Munitić, A. (1989). Kompjuterska simulacija uz pomoć sistemske dinamike (Computer Simulation using System Dynamics). Split: Brodosplit. 


\section{LIST OF ACRONYMS:}

GR - economic growth,

IK - intellectual capital,

INV - investment,

IST - research worker,

KOR - corruption,

LJK - human capital,

MK - moral capital,

$\mathrm{N}$ - unemployment,

OB -education,

$\mathrm{O}$ - tertiary education,

PK - psychological capital,

POP - population,

POV - government institution credibility,

$\mathrm{PR}$ - productivity,

RIND - industry,

RKD - capital goods,

$\mathrm{RR}$ - work resources,

SE - grey economy,

SK - social capital,

SGR - relative change of economic growth rate,

SIK - relative change of intellectual capital rate,

SLJK - relative change of human capital rate,

SMK - relative change of moral capital rate,

STK - relative change of technological capital rate,

SSK - relative change of social capital rate,

TK - technological capital,

TNZ - technology of advanced countries. 